\title{
Study on modification and desulfurization performance of a molybdenum-based catalyst
}

Yuming Tu, Tenghui Li, Guojia Yu, Lu Wei, La Ta, Zhiyong Zhou*, and Zhongqi

Ren*

College of Chemical Engineering, Beijing University of Chemical Technology, Beijing 100029, China

*Corresponding author: +86-10-64434925, renzq@mail.buct.edu.cn (Zhongqi Ren); zhouzy@mail.buct.edu.cn (Zhiyong Zhou)
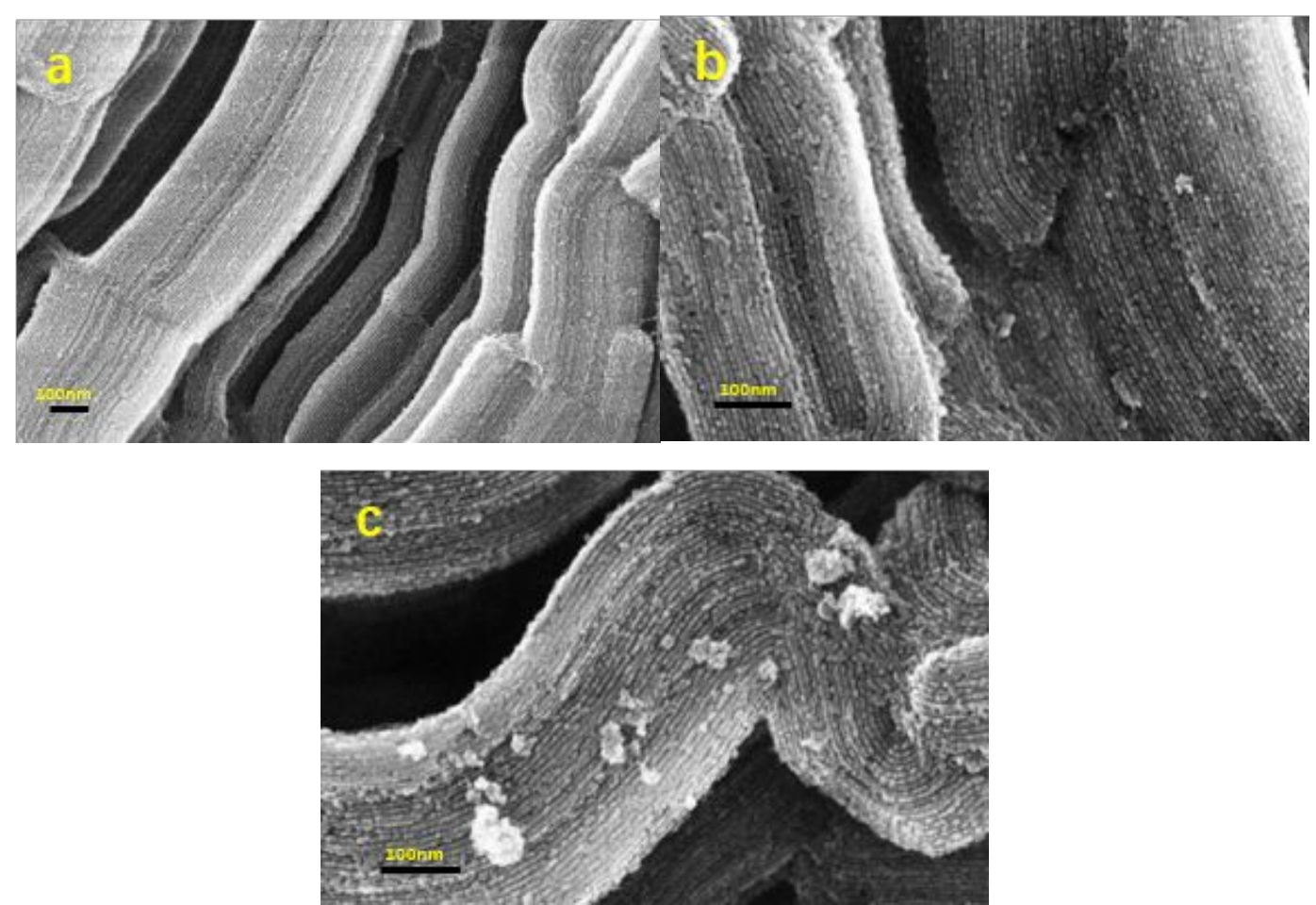

Figure S1. The SEM images of $\mathrm{MoO}_{3} / \mathrm{SBA}-15$ catalysts with different $\mathrm{MoO}_{3}$ contents. (a) $0 \mathrm{wt} \%$, (b), $15 \mathrm{wt} \%$ and (c) $25 \mathrm{wt} \%$. 

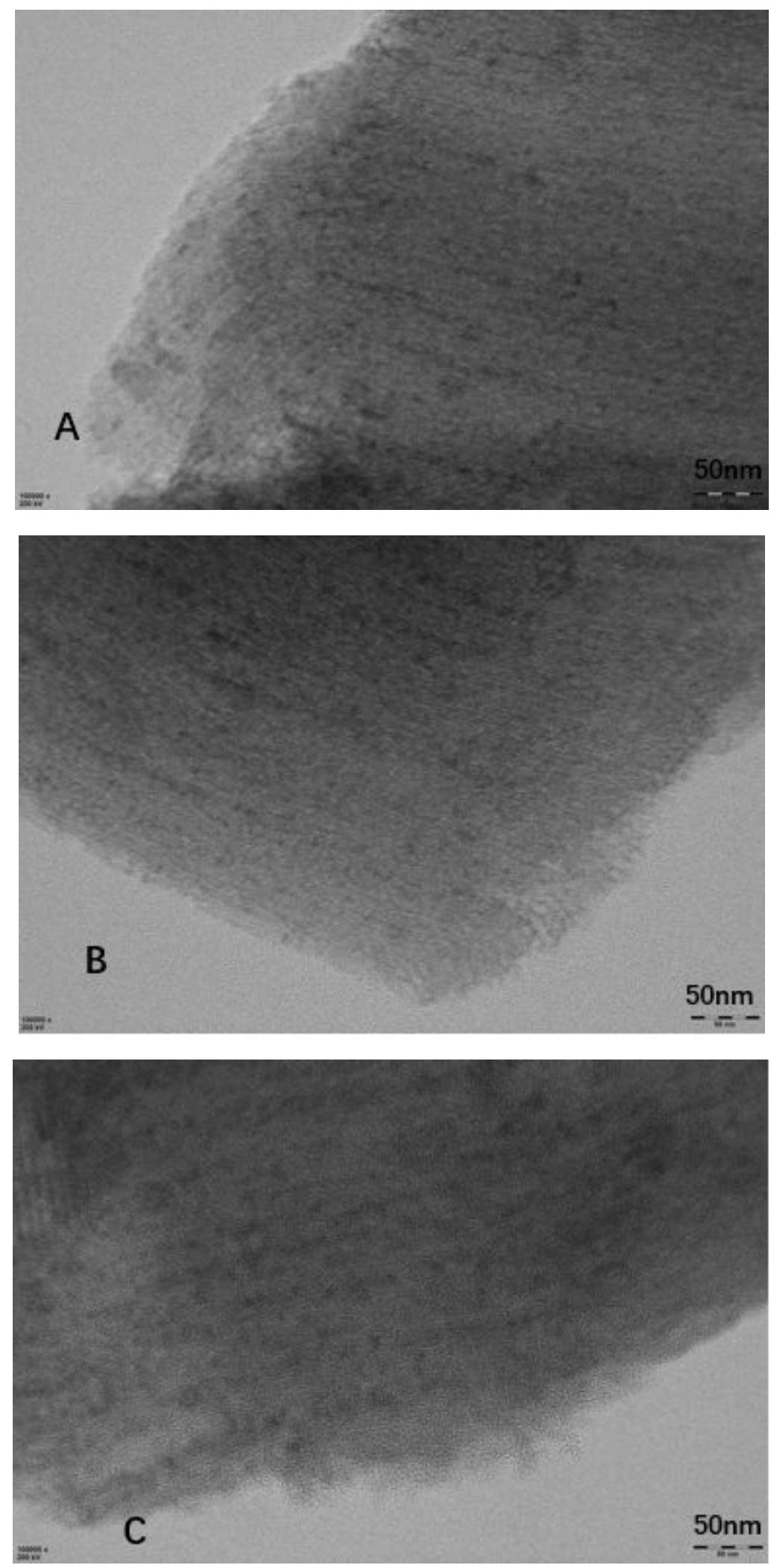

Figure S2. HRTEM micrographs of catalysts: (A) $\mathrm{MoO}_{3} / \mathrm{SBA}-15$; (B) $\mathrm{Na}-\mathrm{MoO}_{3} / \mathrm{SBA}-15$; (C) Ce-MoO $3 / \mathrm{SBA}-15$. 


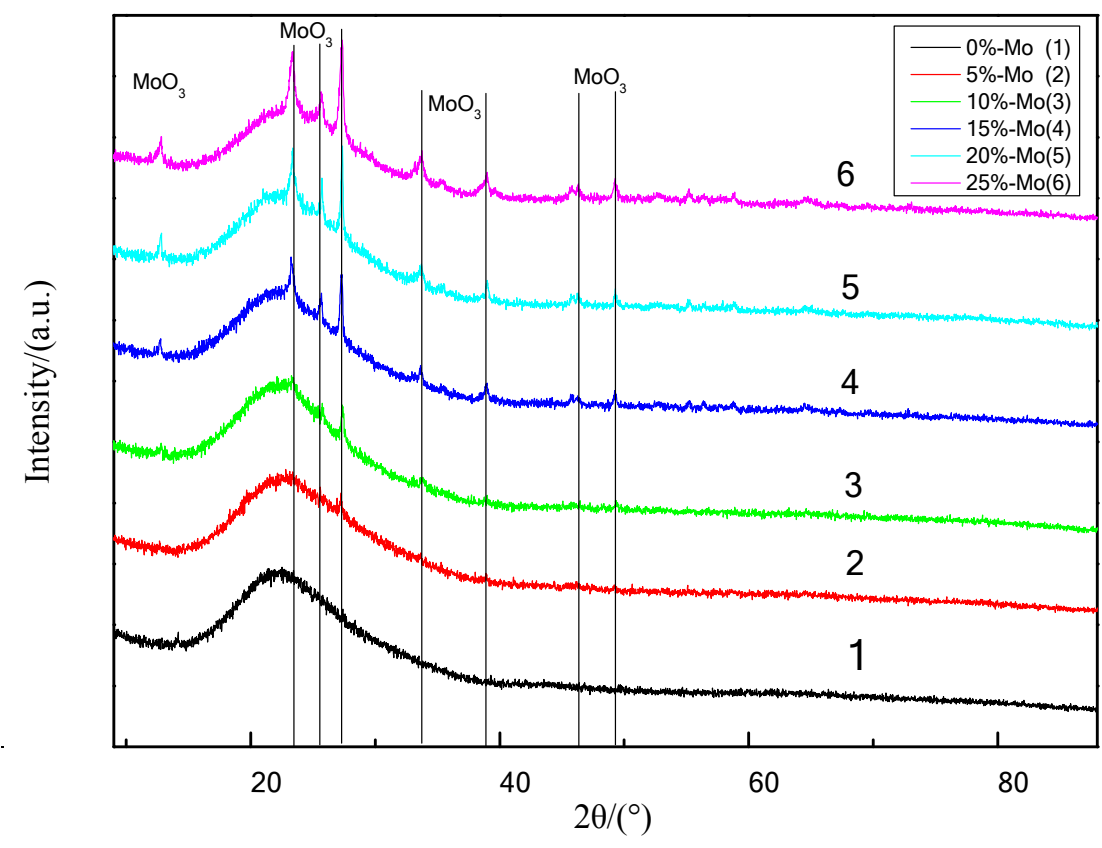

Figure S3. XRD patterns of $\mathrm{MoO}_{3} / \mathrm{SBA}-15$ catalyst.

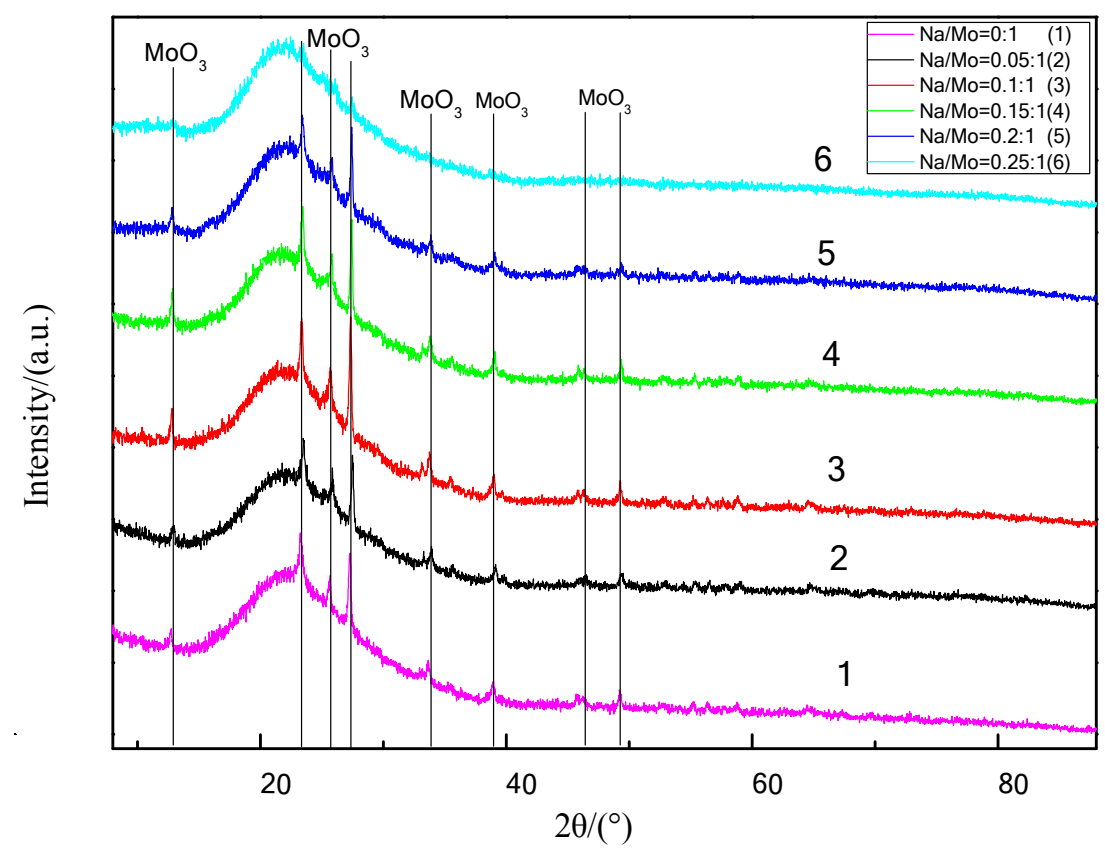

Figure S4. XRD patterns of $\mathrm{Na}-\mathrm{MoO}_{3} / \mathrm{SBA}-15$ catalyst. 


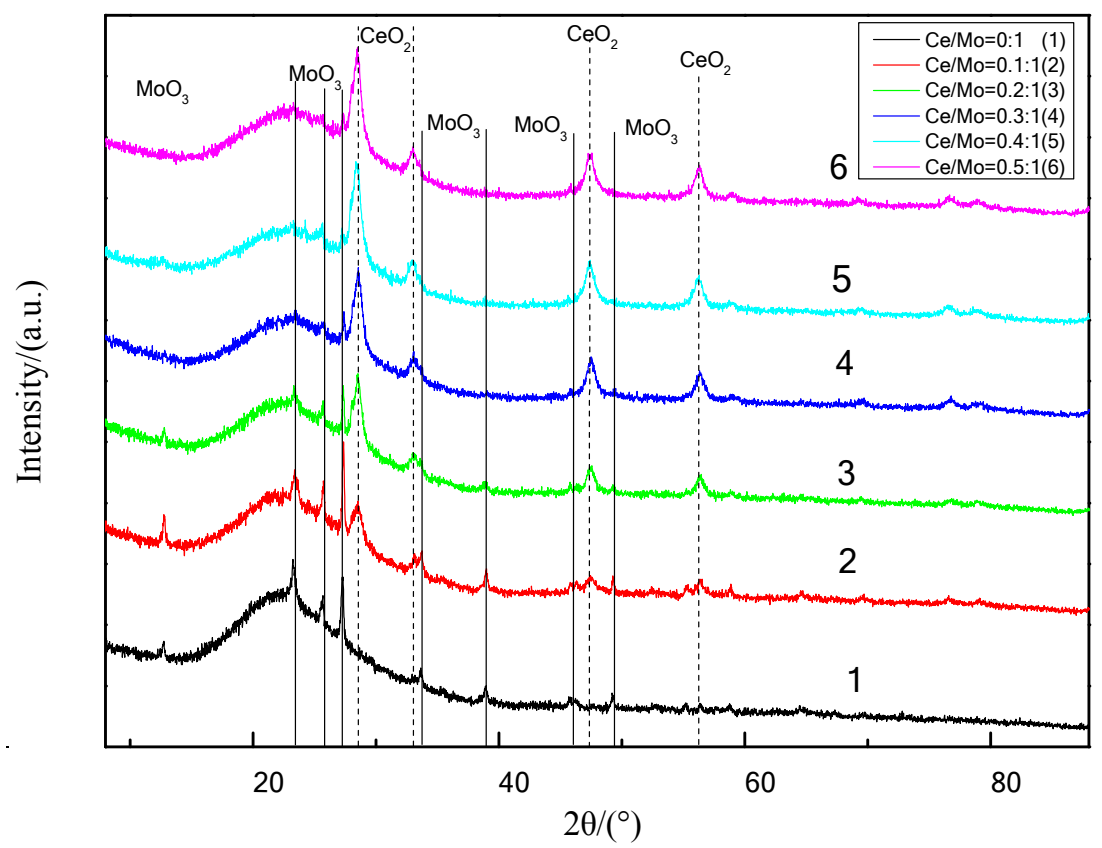

Figure S5. XRD patterns of $\mathrm{Ce}-\mathrm{MoO}_{3} / \mathrm{SBA}-15$ catalyst.

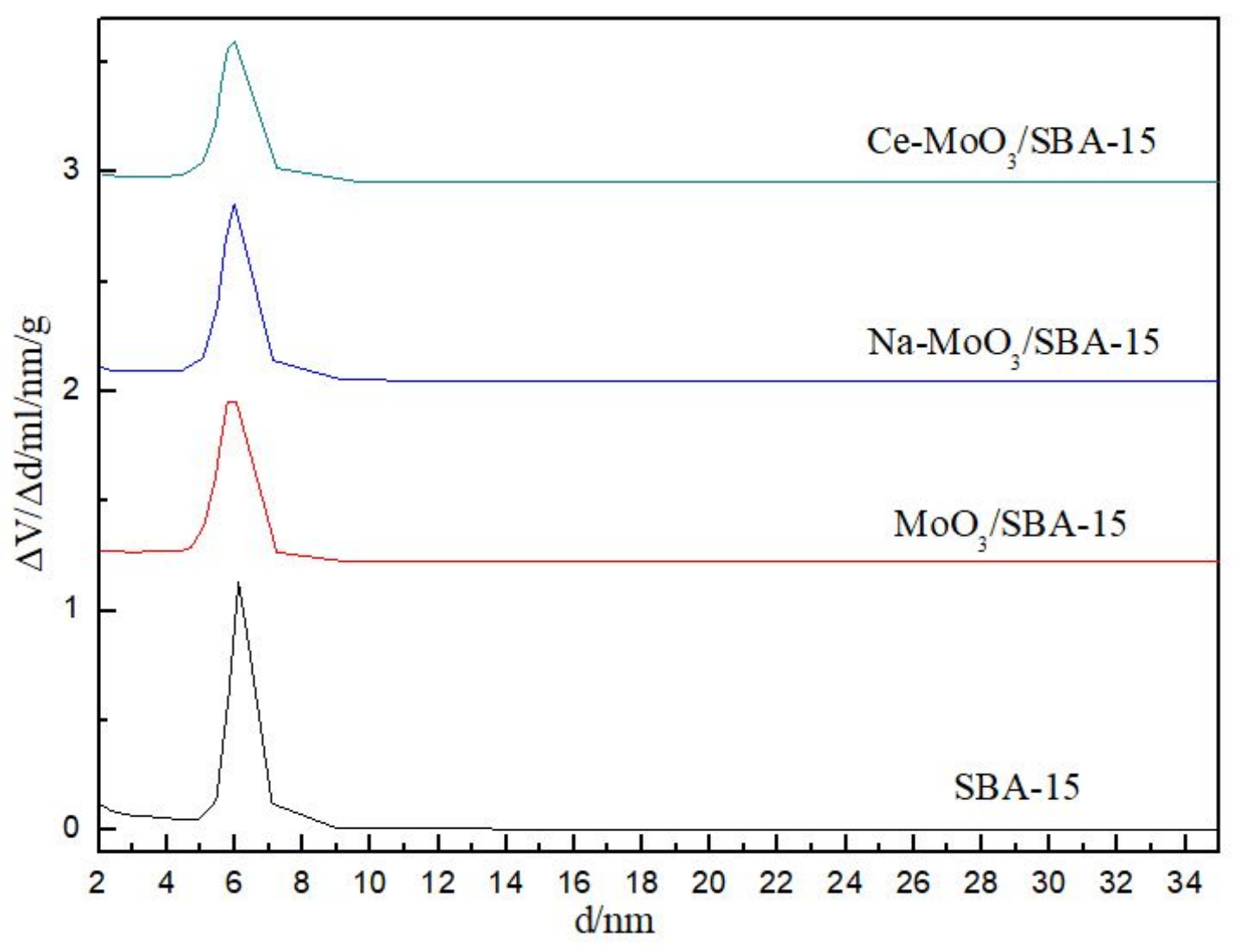

Figure S6. The pore size distribution curves of catalysts. 